\title{
El impacto del nuevo derecho del mar en la evolución de la organización internacional
}

\section{INTRODUCGION}

En Ios últimos años la literatura sobre derecho del mar ha sido tan prolifera que es casi imposible intentar conocer todo lo que se ha escrito sobre el tema. La mayor parte de los estudios publicados están dedicados al análisis de los nuevos conceptos tales como los de zona económica exclusiva, patrimonio común de la humanidad y paso en tránsito por los estrechos que, aunque de formación reciente, han llegado a convertirse en ideas fundamentales del nuevo orden jurídico de los océanos.

Llama la atención, sin embargo, que el desarrollo de un nuevo sector del derecho del mar que introduce numerosos y profundos cambios en el orden existente no haya atraído el interés de los autores en la medida que su novedad lo merece. Me refiero a los aspectos institucionales del nuevo derecho del mar. Con la entrada en vigor de la Convención, aprobada por la Tercera Conferencia de las Naciones Unidas sobre Derecho del Mar el 30 de abril de 1982, se pondrá en funcionamiento un nuevo mecanismo institucional que desde más de un punto de vista aparejará cambios revolucionarios en la historia de la organización internacional.

El origen de esta historia se ubica, para la mayoría de los autores, en la segunda mitad del siglo XIX cuando se crearon las primeras "uniones internacionales", aunque según otras opiniones las raíces de la organización internacional moderna se remontan a las primeras comisiones fluviales internacionales que funcionaron a partir de las primeras décadas de dicho siglo.

Desde entonces se produjo un extraordinario desarrollo de la organización internacional como consecuencia de la revolución científica y tecnológica operada a lo largo de ese período, en particular, después de la Segunda Guerra Mundial. Problemas que en cierto momento histórico eran susceptibles de ser considerados dentro

* Las opiniones contenidas en este trabajo son personales y no representan necesariamente la posición de la oficina para la que trabaja el autor. 
de un marco local o nacional adquirieron una dimensión internacional que reclamó la cooperación entre los Estados para su adecuada solución. Dado que los problemas internacionales requieren una atención continua, el sistema de conferencias diplomáticas resultó insuficiente y la cooperación, para ser efectiva, debió hacerse en forma permanente e institucionalizada, es decir, a través de organizaciones internacionales. Las necesidades de la vida internacional fueron imponiendo, poco a poco, el establecimiento de organismos de cooperación que los Estados no tuvieron otra alternativa que aceptar en un mundo cada vez más interdependiente en el cual las soluciones unilaterales resultan insuficientes.

Consecuentemente, las organizaciones internacionales se han multiplicado, su estructura se ha hecho más compleja, sus funciones más variadas y sus poderes más amplios.

En tanto que las antiguas oficinas internacionales, en las que participaba un grupo reducido de Estados, funcionaron en algunos centros europeos, generalmente ignoradas por la opinión pública, con presupuesto y personal mínimos, en la actualidad la organización internacional se hace presente tanto en las grandes capitales como en los más remotos rincones del mundo, movilizando cuantiosos recursos humanos y financieros, y se ha transformado, a pesar de sus limitaciones, en protagonista principal e indispensable de la vida internacional contemporánea. Sus funciones ya no son sólo las de centralizar y difundir información; en nuestros días la organización internacional informa, asesora, recomienda, asiste, administra, dicta normas, juzga y a veces hasta sanciona. Su competencia se ha expandido más allá de los sectores que tradicionalmente fueron objeto de cooperación internacional, tales como las comunicaciones, la salud y la protección de la propiedad industrial y artística, para cubrir prácticamente todos los aspectos de la actividad humana.

El desarrollo y la expansión de las instituciones internacionales es, sin duda, uno de los hechos más importantes de la vida internacional contemporánea. Pero esta transformación no se ha operado a través de cambios abruptos sino en forma progresiva. Se trata de un proceso evolutivo en que las transformaciones se han efectuado de manera gradual, a veces de modo casi imperceptible. Tal vez pudiera señalarse la creación de la Sociedad de las Naciones - resultante del fracaso del sistema de conferencias que prevaleció durante el siglo $\mathrm{XrX}$ - como la única ruptura en un proceso de cambio gradual. La Sociedad de las Naciones fue la primera tentativa de dotar a la comunidad internacional con un orden político-legal de carácter permanente y con vocación universal, cuyo fundamento no era la voluntad de un Estado, o de un grupo de Estados, sino la de todos los miembros de dicha comunidad. Las Naciones Unidas representó un significativo paso adelante en la evolución de la organización internacional, y su Carta constitutiva procuró evitar los 
Felipe H. Paolillo / El impacto del nuevo derecho del mar en la evolución...

errores y superar las debilidades de su predecesora, pero en rigor no constituye un apartamiento radical del modelo sobre el cual se inspiró.

Ahora estamos en los umbrales de otro cambio revolucionario en la historia de la organización internacional. Algunos de los aspectos institucionales del nuevo orden jurídico del mar tendrán, sin duda, grandes repercusiones en la evolución futura de la organización de la comunidad internacional. En este estudio se examinan algunos de esos aspectos tal como ellos se reflejan en el texto de la Convención sobre el Derecho del Mar recientemente adoptada.

\section{LAS INSTITUGIONES EN EL NUEVO DEREGHO DEL MAR}

Corresponde señalar, ante todo, que por primera vez las cuestiones institucionales constituyen un capítulo fundamental del derecho del mar. A diferencia del régimen jurídico que ha regido hasta ahora en los océanos, el régimen aprobado por la Tercera Conferencia requiere la existencia de instituciones internacionales encargadas de asegurar la observancia y la aplicación de sus normas.

Hasta ahora el derecho del mar estaba constituido por un conjunto de principios y de normas de origen consuetudinario o convencional cuyo cumplimiento quedaba enteramente en manos de los Estados; por tal razón la creación de instituciones para asegurar el cumplimiento de dichas normas no era necesaria. Desde el punto de vista institucional sólo podrían señalarse los procedimientos para la solución de controversias contenidos en las Convenciones de Ginebra de 1958. Dichos procedimientos están previstos en el artículo 9 de la Convención sobre Pesca y Conservación de los Recursos Vivos de la Alta Mar y en el Protocolo Facultativo firmado conjuntamente con las cuatro Gonvenciones. Ambos instrumentos fueron ratificados por un escaso número de Estados y los procedimientos de solución de controversias previstos en ellos no fueron utilizados.

Existen naturalmente varios organismos dentro de la familia de las Naciones Unidas que tienen responsabilidades en materias relacionadas con el uso y la explotación de los océanos, tales como la FAO, IMCO, UNEP, GOI, etc., así como numerosos organismos que funcionan fuera del marco de la ONU, entre los cuales se destacan las comisiones bilaterales o regionales de pesca. Pero será solamente con la entrada en vigor de la reciente Convención sobre el Derecho del Mar que las instituciones aparecerán como elementos fundamentales integrantes del orden jurídico de los océanos. El nuevo régimen regula no sólo los espacios marítimos sometidos a la jurisdicción nacional (mar territorial, zona económica exclusiva, plataforma continental) y el alta mar, que se rige por el principio de la libertad de los mares, sino también la zona de los fondos marinos y oceánicos y su subsuelo más allá de la jurisdicción nacional (deno- 
minada Zona en la Convención), a la que se le reconoce el carácter de "patrimonio común de la humanidad" (Art. 136). Aunque la Convención no define este concepto, es claro que el mismo excluye tanto el principio de soberanía como el de libertad. El "patrimonio común de la humanidad" es una nueva concepción legal para cuya aplicación se requiere la existencia de instituciones internacionales.

En el párrafo 9 de la Declaración de Principios ${ }^{1}$ se preveráa tal necesidad al establecerse que el régimen internacional aplicable a la Zona y sus recursos ha de incluir "un mecanismo internacional apropiado para hacer efectivas sus disposiciones", y ha de prever, "entre otras cosas, el aprovechamiento ordenado y sin riesgos y la administración racional de la Zona y sus recursos". La Convención crea y regula dicho mecanismo, al que se designa "Autoridad Internacional de los Fondos Marinos", que en adelante llamaremos "Autoridad".

Conviene aclarar que los aspectos institucionales del futuro régimen no se agotan con el establecimiento de un organismo para la Zona. Aparte de los numerosos organismos y procedimientos que integran el sistema de solución pacífica de controversias y que constituyen por sí mismos un importante desarrollo institucional, múltiples disposiciones de la Convención se refieren al rol de otros órganos o instituciones, existentes o a crearse en el futuro, en la aplicación de sus disposiciones. Además, la Convención crea la Comisión de Límites de la Plataforma Continental que como su denominación lo indica desempeñará importantes funciones en la determinación de los límites exteriores de la plataforma (artículo 76, párrafo 8, y Anexo II).

Cabe señalarse también la creación de una Comisión Preparatoria (Resolución I) constituida por un mínimo de 50 Estados signatarios de la Convención, encargada de adoptar las medidas y hacer los arreglos necesarios para asegurar que la Autoridad y el Tribunal Internacional del Derecho del Mar empiecen a funcionar efectivamente inmediatamente después de que la Convención entre en vigor. Se trata de un organismo provisional cuya existencia cesa con la entrada en vigor de la Gonvención, cuando la Asamblea de la Autoridad concluya su primera sesión (párrafo 12). La Comisión Preparatoria es un ejemplo atípico de arreglo provisional que se aparta de sus precedentes debido a la complejidad y a la naturaleza de las funciones que se le han asignado, en particular aquellas que se refieren a la concesión del estatuto de "inversor pionero" (Resolución II). Por ello la Comisión Preparatoria ofrece un enorme interés desde el punto de vișta legal e institucional.

2Declaración de Principios que regulan los fondos marinos y oceánicos y su subsuelo fuera de los Ilmites de la jurisdicción nacional (resolución 2749 (xxv) de la Asamblea General) . 
Pero es en las disposiciones que establecen la Autoridad en donde sé encuentran los aportes más novedosos y en algunos aspectos totalmente originales con que là Convención del Derecho del Mar contribuye al desarrollo de la organización internacional.

A primera vista la Autoridad parece estar organizada de acuerdo a los principios tradicionales de la organización internacional. En efecto, se trata de una organización intergubernamental con personalidad jurídica internacional, cuya estructura orgánica básica consiste en los tres órganos que con el mismo o diferentes nombres conforman la estructura orgánica de la mayor parte de las organizaciones internacionales: la Asamblea, el Consejo y la Secretaría.

La Asamblea está integrada por todos los Estados Partes de la Cộnvención, se reúne por lo menos una vez al año y desempeña las funciones de carácter general del tipo que normalmente se atribuyen a los órganos legislativos o deliberantes de otros organismos internacionales (artículo 160). En la Asamblea cada Estado tiene un voto y las decisiones son adoptadas por mayoría o por dos tercios de los miembros presentes y votantes según se trata de cuestiones de procedimiento o de fondo (Art. 159).

El Consejo es un órgano de integración restringida, organizado de modo que pueda reunirse con la frecuencia que requieran los asuntos de la Autoridad, y en todo caso por lo menos 3 veces al año, y encargado de realizar funciones ejecutivas y de asegurar el cumplimiento de las disposiciones de la Convención y la ejecución de las políticas adoptadas por la Asamblea (Arts. 161 y 162)

La Secretaría está integrada por un Secretario General y el personal que la Autoridad requiera. Su estatuto y funciones no se diferencian de aquellos de las secretarías de la mayor parte de los organismos internacionales (Art. 166 y sgtes.).

Desde el punto de vista orgánico la Autoridad sigue el modelo tradicional de las organizaciones internacionales de carácter intergubernamental. Sin embargo, a poco que se examine el texto de la Convención con mayor detenimiento aparecen características que representan en algunos casos un apartamiento radical con respecto a los antecedentes existentes y que, tomados en conjunto, permiten afirmar que con el establecimiento de la Autoridad se abre un nuevo capítulo en la historia de la organización internacional. En los párrafos siguientes se examinan las cuatro características que a nuestro juicio presentan mayor interés y que se relacionan con los siguientes aspectos:

a) El carácter representativo de la Autoridad;

b) La naturaleza de sus cometidos;

c) La composición y el sistema de votación del Consejo, y

d) La sujeción de la actividad de la Autoridad a un control de legalidad. 
La Autoridad representa a la humanidad. El artículo 137, párrafo 2, dispone que: "Todos los derechos sobre los recursos de la Zona pertenecen a toda la humanidad en cuyo nombre' actuará la Autoridad". Del mismo modo el artículo 153, que establece el sistema de exploración y explotación de la Zona y sus recursos, dispone que la Autoridad organiza, realiza y controla las actividades en la Zona "en nombre de toda la humanidad". EI artículo 140 formula otro principio cardinal del nuevo orden: el de que las actividades en la Zona se realizarán en beneficio común de la humanidad.

La humanidad, pues, aparece como titular de un interés directo, de contenido económico, que está por encima de los intereses particulares de los Estados, y que es más que la mera suma de esos intereses.

La humanidad es una entidad abstracta e indivisible que carece de medios institucionalizados de expresión $\mathrm{y}$, sobre todo, de una dimensión jurídica real. El ejercicio efectivo de los derechos que la Declaración de Principios y la Gonvención le reconocen está supeditado a la existencia de una real capacidad de acción de la que, por el momento, la humanidad carece. Por su naturaleza, ella no podrá ejercer estos derechos de modo directo, por Io cual deberá valerse de representantes o intermediarios. ¿Pero quién representa a Ia humanidad? ¿A través de qué personas o entidades, por medio de qué mecanismos puede ejercer los derechos de que es titular?

Ningún Estado o grupo de Estados posee títulos para asumir la representación de la humanidad, ni ningún otro sujeto existente de derecho internacional tiene competencia para desempeñar dicha función. Sin embargo, los Estados son las únicas instituciones que, actuando conjuntamente, pueden lograr el máximo grado de representatividad. Por eso es que la Autoridad se ha concebido como una organización de naturaleza intergubernamental, con vocación universal. La Autoridad estará integrada por Estados, representados por sus gobiernos, y sus decisiones no serán más que la expresión de la voluntad colectiva de esos gobiernos. En consecuencia, la efectividad de la Autoridad estará supeditada al cumplimiento cabal de su vocación universalista, esto es, al hecho de que llegue a estar integrada por todos Ios Estados, o por el mayor número posible de ellos, para asegurar de este modo una fiel representación de la humanidad.

En cierto modo la Autoridad tiene un doble rol que ninguna otra organización internacional, ni siquiera la oNU, ha tenido hasta el presente: por un lado constituye el foro de expresión y de negociación del conjunto de Estados Partes de la Convención. La Autoridad es el instrumento internacional por conducto del cual los 
Estados Partes organizan y controlan la actividad que se lleven a efecto en la Zona, según se expresa en el artículo 157, párrafo 1. Entre la Autoridad y los Estados Partes existe una relación semejante a la que vincula cualquier otra organización internacional con sus miembros. Pero la Autoridad es algo más que el medio de expresión colectiva de sus miembros; es, además, el órgano que representa a la humanidad. Es obvio que no es posible identificar a la humanidad con la suma de los Estados Partes ni siquiera cuando el número de éstos coincida con el número de Estados que forman la comunidad internacional.

La humanidad incluye no sólo a los pueblos sujetos a la jurisdicción de los Estados que serán Partes de la Convención, y, en consecuencia, miembros de la Autoridad, sino además a los pueblos de los Estados que no hayan ratificado la Convención y a aquellos que no se hayan organizado todavía en forma de Estados independientes.

Se plantean a este respecto dos problemas. El primero es el de determinar quiénes van a recibir los beneficios resultantes de la explotación de la Zona y de sus recursos. Sobre este punto el artículo 140 establece que las actividades de la Zona se realizarán en beneficio de toda la humanidad "independientemente de la ubicación geográfica de los Estados, ya sean ribereños o sin litoral, y prestando consideración especial a los intereses y necesidades de los Estados en desarrollo y de los pueblos que no hayan logrado la plena independencia u otro régimen de aútonomía reconocido por las Naciones Unidas de conformidad con la resolución 1.514 (xv) y otras resoluciones pertinentes de la Asamblea General".

Un problema diferente es el de determinar qué sujetos, además de los Estados, podrán ser Partes de la Convención y por lo tanto miembros de la Autoridad. La participación en la Convención fue uno de los puntos que más se discutieron en la Conferencia. Varias categorías de entidades expresaron su aspiración de formar parte de la Convención en condiciones idénticas o similares a las de los Estados. Estas categorías son las siguientes:

1. Estados asociados autónomos tales como los Estados Federarados de Micronesia, las Islas Marshall, las Islas Cook y Neue y Papua;

2. Los territorios no independientes;

3. Los movimientos nacionales de liberación;

4: Las organizaciones internacionales tales como la Comunidad Económica Europea.

La admisibilidad de estas entidades como Partes de la Gonvención se hizo depender de dos factores: en primer lugar, del hecho de que estas entidades tuvieran competencia en las materias regu- 
ladas por la Convención; y, en segundo lugar, del hecho de poseer capacidad para concertar tratados en relación a esas materias. Aplicando estos dos criterios fue relativamente fácil convenir en que además de los Estados, los Estados asociados autónomos y los territorios que no hayan alcanzado plena independencia de acuerdo con la resolución 1.514 (xv) de la Asamblea General tienen capacidad legal para suscribir y ratificar la Convención.

Con sujeción a ciertas condiciones establecidas en el Anexo Ix, las organizaciones internacionales a las que sus miembros hayan transferido competencia en materias regidas por la Gonvención también podrán firmar la Convención y confirmar formalmente o adherirse a la misma, lo cual les asegurará su condición de Partes. También se reconoció a Namibia el derecho de firmar y ratificar la Convención por medio del Consejo de las Naciones Unidas para Namibia (artículo 305, párrafo 1 b) y artículo 306).

El caso más difícil de solucionar fue el de los movimientos nacionales de liberación reconocidos por las Naciones Unidas y por las organizaciones internacionales regionales pertinentes. Ciertos sectores de la Conferencia reclamaron el reconocimiento del derecho de dichos movimientos a ser Partes de la Convención.

Finalmente, frente a la oposición de otros sectores de la Conferencia, se llegó a una solución de compromiso mediante la cual los movimientos nacionales de liberación que han participado en la Conferencia tendrán el derecho de firmar el Acta Final (pero no la Convención) en su capacidad de observadores (resolución IV), así como de participar en la misma calidad en la Autoridad (artículo 156, párrafo 3).

El carácter representativo de la Autoridad incidirá de varias maneras sobre su naturaleza y su funcionamiento. La idea de representar el interés común de la humanidad por una organización internacional altera el esquema tradicional de relaciones que el legislador internacional enfrenta habitualmente al formular las reglas que gobiernan una organización internacional. En este caso no se trata de asegurar el equilibrio entre los intereses contradictorios de los Estados, sino de coordinar, o más bien subordinar, los intereses de éstos al interés superior y prioritario de la humanidad.

Como la satisfacción del interés de la humanidad constituye el móvil prevalente de las actividades de la Autoridad, la acción internacional que ella desarrolle estará dotada de una unidad de propósito que, junto a la peculiar naturaleza de sus funciones (producción y administración de recursos naturales), requerirá de los Estados participantes una actitud más cooperativa que la que se requiere en otras organizaciones internacionales. Esta es una condición indispensable para asegurar la efectividad de la nueva organización.

El funcionamiento efectivo de la Autoridad exige una nueva 
concepción de la cooperación internacional, basada en la idea de que la solución de los problemas de desarrollo del tercer mundo ya no se plantea sólo en términos de ayuda, asistencia o preferencias. Ahora se requiere un nuevo enfoque que implica el reordenamiento general de las relaciones internacionales. La naturaleza y el alcance de los problemas económicos y sociales que afectan al mundo son tales que el esfuerzo que se realice para solucionarlos sólo puede provenir de la acción conjunta y general de todos los países. La responsabilidad por la solución de los problemas mundiales de desigualdad, pobreza, contaminación, inflación e inseguridad no puede quedar en manos de ciertos países actuando aisladamente, o de ciertos grupos de países. Se requieren formas de cooperación global en las que se comprometen la voluntad y la acción de todos los protagonistas que actúan en el escenario internacional, lo cual descarta el enfoque tradicional de la cooperación fluyendo en una sola dirección, de los países industrializados (sujetos donantes) a los países en desarrollo (sujetos recipientes).

Este cambio de enfoque que conduce de la cooperación tradicional de carácter "asociativo", está alimentada en gran parte por la idea de que los países con diferente grado de desarrollo o con diferente sistema económico tienen, en el mediano y largo plazo, más intereses comunes que contrapuestos. La existencia de intereses mutuos prevaleciendo por encima de intereses opuestos constituye la premisa de la que se derivan vinculaciones de carácter asociativo entre países industrializados y países en desarrollo.

En la nueva forma de cooperación que la Convención del Derecho del Mar parece anunciar, todos los países se unen en una empresa común para la consecución del mismo objetivo, que es el de explotar los recursos minerales de los fondos marinos, proporcionar al mundo ciertos productos básicos indispensables, y distribuir equitativamente los beneficios de dicha actividad. No existen en este caso donantes y recipientes sino socios que se unen para administrar y explotar un bien que les pertenece en común. Es una cooperación que entraña una asociación creadora, una participación activa y convergente de todos los protagonistas. Ello exige la disposición de todos los Estados para combinar sus recursos financieros y tecnológicos, su capacidad empresarial, su mano de obra, y sobre todo su voluntad política, de modo tal que puedan desarrollarse por primera vez en la historia de las relaciones internacionales, actividades industriales y comerciales conducidas por instituciones internacionales de naturaleza intergubernamental y destinadas a beneficiar a todos los habitantes del planeta.

El sistema establecido en la Convención de acuerdo con el cual todos los Estados Partes participan en la administración y explotación de los recursos de la Zona por medio de la Autoridad que actúa en función de los intereses de la humanidad, puede constitufr 
el modelo de una nueva forma de cooperación aplicable en el futuro a otras áreas de la actividad humana.

\section{LOS COMETIDOS DE LA AUTORIDAD}

La Autoridad tiene por cometido el de organizar, controlar y conducir actividades de exploración y explotación de los recursos de la Zona internacional. Se trata pues de la administración y producción de bienes económicos. En realidad, las actividades de explotación de los recursos de la Zona se harán mediante dos formas: Por un lado, ellas serán realizadas por los Estados o por' empresas estatales o privadas que deberán celebrar a estos efectos contratos con la Autoridad. En estos contratos se especificarán los derechos y las obligaciones del contratista, quien, entre otras cosas, deberá de realizar una serie de pagos a la Autoridad a cambio del derecho de acceder a la Zona y explotar sus recursos, así como a transferir a la Autoridad, si ésta lo solicita y en ciertas condiciones, la tecnología que vaya a utilizar en sus operaciones. Por otro lado, la Autoridad podrá realizar por su cuenta operaciones de explotación a través de un órgano especial llamado la Empresa.

En el cumplimiento de estos cometidos la Autoridad va a ejercer vastos poderes normativos y administrativos en lo que se refiere a la organización, control y conducción de las operaciones de minería oceánica. Entre otras cosas, la Autoridad examinará y decidirá sobre los planes de trabajo que propongan los solicitantes de contratos para la conducción de actividades en la Zona; negociará y concluirá contratos con Estados Partes ý otras entidades; podrá participar en arreglos conjuntos para explotar los recursos, y se embarcará ella misma, por su cuenta y responsabilidad, en operaciones de exploración y explotación. No habrá operación en la Zona que la Autoridad no conduzca, en la que ella no participe o que no haya sido autorizada por ella.

Se trata de funciones que en cierto modo no tienen precedentes en la historia de la organización internacional, ya que es la primera vez que se atribuye a un organismo intergubernamental con vocación universal la tarea de administrar recursos naturales.

Existen sí ciertos antecedentes de organismos internacionales de carácter intergubernamental que tienen alguna semejanza con la Autoridad en la medida en que también poseen competencias relacionadas con la administración de recursos. Se trata de los bancos internacionales tales como el Banco Internacionảl de Reconstrucción y Fomento, el Banco Interamericano de Desarrollo y otros bancos regionales. Podría también citarse la Agencia Internacional de Energía Atómica y en cierto modo xnrelsat. Pero existen diferencias entre estos organismos y la Autoridad en lo que respecta a los objetivos, al alcance y la naturaleza de sus poderes, a la estructura 
orgánica $\mathrm{y}$, en particular, al régimen jurídico de los recursos administrativos, de modo que no parece que puedan establecerse comparaciones útiles entre aquéllos y ésta. En todo caso puede afirmarse sin duda que no existe un precedente de organización intergubernamental universal cuyo cometido sea el de la producción y administración de recursos naturales con fines comerciales.

Para que la Autoridad pueda cumplì con dicho cometido se crea la Empresa. La Empresa no es un órgano principal de la Autoridad, pero tampoco puede considerarse un órgano subsidiario, de acuerdo con el texto de la Convención (artículo 158). No obstante ello en la Convención se le denomina órgano más de una vez. Se trata del órgano a través del cual Ia Autoridad "realizará directamente las actividades de exploración y explotación de los recursos de la Zona, así como el transporte, el tratamiento y la comercialización de los minerales extraídos de la Zona" (artículo 170, párrafo 1). A los efectos prácticos, la determinación de la categoría de órgano a la que la Empresa pertenece carece de importancia en la medida en que su vinculación con la Autoridad está descrita con bastante claridad en el texto. Pero no deja de ser curioso el hecho de que siendo un "órgano" como repetidamente lo denomina la Convención, posee" no sólo autonomía en la realización de las operaciones sino además personalidad jurídica independiente (artículo 170, párrafo 2). En el Anexo Iv, que contiene el Estatuto de la Empresa, se dispone que ella tendrá capacidad jurídica para el desempeño de sus funciones y en particular la capacidad de celebrar contratos, arreglos conjuntos, inclusive acuerdos con Estados y organizaciones internacionales; además, puede adquirir, arrendar y poseer bienes muebles e inmuebles, y puede ser parte en acciones judiciales en nombre propio (artículo 13, párrafo 2). La Empresa no será responsable por los actos o las obligaciones de la Autoridad ni la Autoridad responsable por los actos o las obligaciones de la Empresa (artículo 2, párrafo 3). La Empresa posee personería y autonomía en un grado tal que resulta difícil considerarla como un órgano más de la Autoridad. En todo caso se trataría de un órgano sui generis, tanto por su condición jurídica como por la naturaleza de su actividad.

El desarrollo de la organización internacional, a juzgar por la forma en que se ha reglamentado a la Empresa de la Autoridad, parece abrirse camino en un sentido similar al de las administraciones públicas nacionales de ciertos países cuando expandieron sus funciones más allá de las clásicas de legislar, ejecutar y juzgar, para entrar en el dominio de la actividad económica comercial. Esta actividad se ha realizado en ciertos casos a través de entidades estatales a la que se les asigna un estatuto especial de autonomía. Es el caso de las "regie" francesas, o de las entidades a las que se 
llama en otros países empresas nacionales, empresas públicas o entes autónomos.

La estructura orgánica de la Empresa no parece ser la más adecuada para la consecución de sus objetivos económicos debido a la importancia del elemento político en el funcionamiento de sus órganos, la Junta Directiva y el Director General.

El Director General será elegido por la Asamblea sobre la base de una candidatura presentada por la Junta que tenga la recomendación del Consejo. La Junta Directiva está integrada por 15 miembros elegidos por la Asamblea sobre la recomendación del Consejo, teniendo debidamente en cuenta' el principio de la distribución geográfica equitativa. El texto contiene disposiciones que procuran asegurar la eficacia y la independencia de la Empresa. Se dice, por ejemplo, en el artículo 5, párrafo 1, del Anexo Iv que los miembros de la Autoridad al proponer los candidatos para la Junta deberán tener presente la necesidad de que los mismos posean el máximo nivel de competencia y las calificaciones necesarias en la esfera pertinente a fin de garantizar la viabilidad y el éxito de la Empresa. EI párrafo 5 de la misma disposición dice que los miembros de la Junta actuarán a título personal y que no solicitarán ni aceptarán instrucciones de ningún gobierno o de ninguna otra fuente. Además el artículo 12 del Estatuto de la Empresa dispone que ésta, al tomar sus decisiones tendrá en cuenta sólo consideraciones de orden comercial.

Sin embargo, la designación de los miembros de la Juntá es hecha por órganos de naturaleza política como lo son la Asamblea y el Consejo; en dicha elección se deberá tener "debidamente en cuenta" el principio de la distribución geográfica equitativa. Es probable que la forma de integración de la Junta, unida al hecho de que la Empresa deberá actuar de conformidad con las políticas generales de la Asamblea y las directrices del Consejo, permita que las consideraciones políticas influyan excesivamente sobre las actividades de la Empresa afectando adversamente su efectividad.

\section{v. LA COMPOSICION Y EL SISTEMA DE VOTAGION DEL CONSEJO}

En sus rasgos generales el Consejo de la Autoridad sigue el modelo de los órganos ejecutivos de otras entidades internacionales: es de composición restringida, sus miembros son elegidos por la Asamblea, órgano plenario de la Autoridad, y sus funciones son de carácter esencialmente ejecutivo, aunque corresponde señalar que no existe en la Gonvención un criterio claro de distribución de competencias entre los órganos de la Autoridad.

Sin embargo, un examen más detallado de las disposiciones que regulan la organización del Consejo nos muestra que éste posee algunas características que si bien no son totalmente originales, le 
confieren a este órgano una fisonomía muy peculiar. Esta peculiaridad se manifiesta en su composición y en los procedimientos de adopción de decisiones.

La composición del Consejo ha sido uno de los temas más debatidos de la Conferencia. Para los países desarrollados un Consejo integrado únicamente sobre la base del principio de la representación geográfica equitativa era inaceptable puesto que ello significaría admitir en dicho órgano una situación de inferioridad numérica que no les permitiría ejercer el control de las decisiones de dicho órgano. Por ello propusieron organizar el Consejo sobre la base de representación de intereses, mayorías concurrentes o especiales, voto ponderado u otros mecanismos que les asegurara un mayor poder en el proceso de adopción de decisiones.

La representación de intereses especiales como principio básico para la composición del Consejo se ha justificado en la necesidad de que este órgano, que será responsable de la dirección cotidiana de los asuntos de la Autoridad, se refleje con la mayor fidelidad posible el contexto político-económico en que va a actuar. Parece lógico que los países que van a hacer las grandes inversiones que la explotación de la Zona requiere, y a correr con los mayores riesgos, tengan una influencia en las decisiones del Consejo acorde con la magnitud de sus intereses. Igual razonamiento puede hacerse con respecto a otros intereses tales como los de los países productores terrestres y los de los consumidores de los minerales que serán extraídos de la Zona.

La representación de ciertos intereses especiales en. los órganos ejecutivos de las organizaciones internacionales no es, por cierto, una idea nueva. A vía de ejemplo puede citarse el Convenio sobre la Organización de la Aviación Givil Internacional, en el que se dispone que en la ințegración del Consejo deberá acordarse la debida representación a los Estados de mayor importancia en el transporte aéreo y a los que más contribuyan a proveer facilidades para la navegación civil internacional; en lạ Organización Consultiva Marítima Intergubernamental cierto número de asientos del Consejo se asignan a los gobiernos de los países con los mayores intereses o intereses substanciales en la producción de los servicios marítimos internacionales y en el comercio marítimo internacional; en la Agencia Internacional de la Energía Atómica los países más adelantados en la tecnología de la energía atómica deberán estar representados en la Junta de Gobernadores.

Sin embargo, la forma en que la Convención ha consagrado la representación de intereses es considerablemente más compleja que en cualquiera de Ios órganos que acabamos de mencionar. El Consejo estará integrado por 36 miembros, la mitad de los cuales serán electos en función de los intereses que representen. Pero estos intereses son múltiples; existen cuatro categorías de miembros repre- 
sentantes de diversos grupos de interés y entre estos grupos están el de los Estados que hayan hecho inversiones en la Zona, aquellos que sean los más importantes consumidores o importadores o exportadores de los minerales que se extraigan de la Zona, los Estados con gran población, los Estados sin litoral o en situación geográfica desventajosa, los Estados productores potenciales y los Estados en desarrollo menos adelantados (artículo 161, párrafo 1).

Ninguna de estas categorías ha sido claramente definida en el texto de la Convención. Es probable que en algunos casos la inclusión de un Estado en un grupo de interés pueda suscitar problemas. Los miembros del Consejo son elegidos por la Asamblea, pero ésta deberá actuar sobre las propuestas formuladas por cada grupo de interés de modo que en el caso de los 18 miembros del Consejo que representan intereses, la función de la Asamblea sería en realidad la de confirmar las propuestas hechas por los grupos respectivos. Los miembros representantes de grupos de interés deberán ser elegidos por la Asamblea en el orden en el que los grupos están enumerados en el artículo 161.

En cuanto a los procedimientos de adopción de decisiones, la fórmula de compromiso que ha sido incorporada en la Convención no puede ser más complicada. Hay por lo menos 5 categorías de cuestiones para cada una de las cuales se requieren mayorías o procedimientos diferentes (artículos 161, párrafo 7, y 162, párrafo 2 j)). Las cuestiones de procedimiento se deciden por mayoría de miembros presentes y votantes; algunas cuestiones de fondo se deciden por dos tercios de miembros presentes y votantes, a condición de que esa mayoría incluya una mayoría de los miembros del Consejo; otras cuestiones de fondo deberán decidirse por una mayoría de tres cuartos de los miembros presentes y votantes con lá misma condición. Dado que los dos tercios o tres cuartos se calculan sobre miembros presentes y votantes y puesto que el mínimo de votos requeridos será la mayoría de los miembros del Consejo, esto es 19, el número de votos requerido para adoptar decisiones sobre cuestiones de fondo será variable, oscilando entre 19 y 27, según sea el número de miembros que asistan a la reunión de votación. Algunas decisiones deberán adoptarse por consenso, y la noción de consenso se define por primera vez en una Convención; se entiende por tal la "ausencia de toda objeción formal" (artículo 162, párrafo 7 a)) Existe un procedimiento de conciliación para asegurar la obtención del consenso en los casos en que en un asunto que deba decidirse por consenso se formule una objeción (artículo 171, párrafo 7 e)). Por último, los planes de trabajo que propongan los Estados o las empresas estatales o privadas para la explotación de los recursos siguen un procedimiento especial que incluye la aprobación tácita o el procedimiento de conciliación que 
se utiliza para asegurar el consenso, según los casos. (Art. 162, párrafo 2 j))

Como puede deducirse de esta descripción sumaria, la composición y los procedimientos de adopción de decisiones del Consejo están regidos por reglas extremadamente complicadas. Esta complejidad no hace más que reflejar las enormes dificultades que han existido para conciliar las posiciones opuestas de los distintos grupos de países en el seno de la Conferencia.

Las dificultades se explican si se piensa que el Consejo está llamado a adoptar decisiones que afectarán importantes intereses económicos e incluso políticos de los Estados. Es cierto que el texto dice que la Asamblea debe ser considerada el órgano supremo de la Autoridad. Pero no podría asegurarse que en la práctica la Asamblea va a ejercer la supremacía que el texto le confiere, en el sentido de ser el órgano que adopte las decisiones más importantes e imponga una orientación a la acción de la Autoridad. La Asamblea está afectada por las debilidades constitucionales que afectan a todos los órganos plenarios de las organizaciones de alcance universal - elevado número de participantes, funcionamiento no permanente, complejidad y lentitud de las deliberaciones. En términos generales, y a riesgo de simplificar excesivamente el problema, puede decirse que la distribución de competencias entre los dos órganos principales de la Autoridad se ha inspirado sobre todo en la idea de asignar a la Asamblea el cometido de trazar las directivas políticas más generales, dejando en manos del Consejo la tarea de asegurar, mediante sus funciones reguladoras, de ejecución y de control, la aplicación efectiva tanto de dichas políticas generales como de las disposiciones de la Convención. Parece inevitable que el Consejo ocupará la posición predominante en la Autoridad, y que sobre ese órgano recaerá el mayor peso y las mayores responsabilidades en la aplicación del régimen de explotación de los recursos de la Zona.

\section{LA SUJECION DE LA AGTIVDDAD DE LA AUTORIDAD A UN GONTROL DE LLA LEGALIDAD}

La cuarta característica de la Autoridad que a nuestro juicio merece ser destacada se relaciona con los procedimientos de solución de controversias. El sistema general de solución de controversias está contenido en la Parte xv de la Convención, cuyas disposiciones, complementadas con las de los Anexos v a virr, establecen un conjunto de principios, órganos y procedimientos que en algunos aspectos representan valiosos aportes al desarrollo del derecho internacional en esta materia.

Paralelamente al sistema general, la Convención establece un sistema especial para la solución de las controversias relacionadas 
con las actividades en la Zona. El establecimiento de este sistema especial en forma separada del sistema general responde al deseo de adecuar los procedimientos de solución a las características propias de cada tipo de controversia. Las controversias relacionadas con las actividades de la Zona presentarán una serie de peculiaridades que las distinguirá de las controversias que surjan con respecto a la interpretación y aplicación de las disposiciones de la Convención que se refieran a otras actividades $u$ otros sectores del medio marino.

En primer Iugar, la Zona y las actividades que se realicen en ella están regidas por un orden particular basado en el principio de que la Zona y sus recursos son el patrimonio común de la humanidad (artículo 136) e integrado por: a) normas convencionales contenidas en la Parte XI de la Convención y sus Anexos; ii) actos adoptados por la Autoridad, y iii) normas de naturaleza contractual acordadas entre la Autoridad y las entidades que operarán en la Zona, al celebrar los contratos de exploración y explotación.

En segundo lugar, puesto que la Zona y sus recursos son el patrimonio común de la humanidad, toda controversia que surja con respecto a ellos interesa a todos los Estados y su solución afecta los intereses de todos, no sólo los de las partes en la controversia. TaI como se expresó en las negociaciones informales, las controversias relacionadas con la Zona conciernen al orden público internacional $y$, por lo tanto, su solución debería de quedar a cargo de una jurisdicción especial que asegurara la formación de una jurisprudencia especializada y unitaria.

En tercer lugar, las controversias que se susciten con relación a las actividades en la Zona involucrarán no sólo a los Estados Partes sino también a otros sujetos que participan en ellas tales como la Autoridad, la Empresa y las personas naturales y jurídicas, nacionales de los Estados Partes o controladas por ellos.

Por último, el régimen de explotación de la Zona asigna un rol preponderante a Ia Autoridad, organismo encargado de administrar la Zona y sus recursos, con capacidad para organizar, controlar y conducir actividades en la misma en nombre de la humanidad (artículos 137, párrafo 2, y 157, párrafo 1). En el ejercicio de estas funciones, la Autoridad puede afectar los derechos de los Estados Partes y de otras entidades que operen en la Zona, por lo cual se entendió indispensable proporcionar a los Estados Partes medios para recurrir contra los actos ilegales de Ia Autoridad.

El sistema especial para la solución de controversias relacionadas con las actividades en la Zona ha sido establecido en los artículos I86 y siguientes de la Convención. Este sistema presenta una serie de características que constituyen, en algunos casos, verdaderas innovaciones en la materia. La institución de una jurisdicción separada cuyo órgano principal es una sala del Tribunal Internacional 
del Derecho del Mar (Sala de Controversia de los Fondos Marinos, en adelante SCFM), la atribución a personas físicas y jurídicas de la capacidad de comparecer ante la SCFM como partes en una controversia, y la competencia de dicho órgano para resolver controversias relativas a actos ilegales de la Autoridad, son aspectos del sistema especial cuyo carácter innovativo no puede pasar desapercibido.

En el artículo 187 de la Convención se enumeran las categorías de controversias que deberán ser sometidas a los procedimientos de solución del sistema especial. Entre ellas se incluyen las controversias entre un Estado Parte y la Autoridad por actos u omisiones de ésta que adolezcan de ciertos vicios de legalidad (apartado b). La inclusión de este tipo de controversia entre aquellas que deben ser sometidas a los procedimientos especiales previstos en los artículos 186 y siguientes constituye uno de los aspectos más interesantes de la Gonvención, ya que significa la aceptación de cierta forma de control de legalidad -ejercido de modo indirecto y con alcances muy limitados ${ }^{2}$ - de los actos de una organización internacional, de lo cual el derecho internacional vigente ofrece muy escasos ejemplos. En todo caso, sería ésta la primera vez que los actos de una organización internacional con vocación universal quedan sometidos a un control semejante.

En efecto, el problema del control de legalidad de los actos de las organizaciones internacionales no ha sido, hasta ahora, objeto de desarrollos significativos ni en la doctrina ni en la práctica, salvo el caso de los actos de ciertas organizaciones económicas regionales tales como la Comunidad Económica Europea.

En la práctica, la mayoría de los instrumentos constitutivos de las organizaciones internacionales no han previsto, de modo expreso, la posibilidad de que sus miembros impugnen la legalidad de sus actos ${ }^{3}$. En los tratados estableciendo varias agencias de las Naciones Unidas se dispone que, salvo que las partes escojan otro procedimiento de solución, las controversias relativas a la interpretación o aplicación de dichos instrumentos deberán de ser sometidas a la Corte Internacional de Justicia, de lo cual se desprende que sólo se ha previsto la posibilidad de que se planteen controversias entre los Estados miembros del organismo, ya que sólo los Estados pueden comparecer ante la Corte (artículo 34 del Estatuto de la cIJ). En algunos casos los órganos de las agencias, debidamente autorizados por la Asamblea General, podrán solicitar a la cIJ opiniones con-

"Sobre esté tema véase del autor: "Solución de Controversias relacionadas con actos de organizaciones internacionảles: El cáso de la Autoridad Internacional de los Fondos Marinos" en...

${ }^{B} G$. D. Bindsehedler: "Différends relatifs dù statut d'un organisme international", Academie de Droit International, Recueil des Cours, 1968, Ir, p. 502: 
sultivas sobre cualquier cuestión jurídica relacioñada con la agencia ${ }^{4}$.

En los casos en que se ha previsto la posibilidad de una controversia entre la institución y sus miembros, se han utilizado dos tipos de soluciones que se basan en diferentes enfoques del problema: o bien se adopta el enfoque "tradicional" aplicándose a la controversia entre la organización y un Estado miembro de los mismos procedimientos previstos para solución de las controversias entre Estados, o bien se organiza un procedimiento especial mediante el cual un órgano judicial realiza el control de la legalidad de los actos de la organización que puede culminar en la declaración de su nulidad (contencioso de anulación).

Este último procedimiento ha sido incorporado únicamente en algunos tratados relativos a organizaciones regionales de integración económica. El ejemplo más interesante se encuentra en el Tratado estableciendo la Comunidad Económica Europea, que confiere a la Corte de Justicia de la Comunidad el poder de controlar la legalidad de ciertos actos del Consejo y de la Comisión (artículos 173 a 176). El Tratado indica qué actos pueden ser impugnados y las causales por las cuales pueden ser declarados nulos (incompetencia, violación de las formas substanciales, violación del Tratado o de cualquier norma de derecho relativa a su aplicación, o desviación de poder); los sujetos que pueden interponer el recurso (Estados miembros, el Consejo o la Comisión de las Comunidades, y las personas físicas o morales bajo ciertas condiciones); el plazo dentro del cual ha de interponerse el recurso (dos meses a contar de la publicación del acto, de su notificación al recurrente o del día en que el recurrente haya tenido noticia del mismo, según el caso), los poderes de la Corte (declaración de que el acto es nulo y no producido) y los efectos de la sentencia (obligación de la institución que adoptó el acto anulado o que se abstuvo ilegalmente de actuar, de adoptar las medidas necesarias para la ejecución de la sentencia). Otro ejemplo del mismo enfoque es el del Tratado creando la Corte de Justicia del Acuerdo de Cartagena, del 28 de mayo de 1979, que instituye un procedimiento de contralor judicial de las decisiones de la Comisión y de las resoluciones de la Junta

"Curiosamente, el recurso a este procedimiento de carácter facultativo y que culmina con una decisión no obligatoria, proporciona el ejemplo más interesante de pronunciamiento de un tribunal internacional sobre la legalidad de los actos adoptados por una organización internacional de carácter universal. A instancias de Liberia y Panamá, la Asamblea de ocm solicitó a la arJ una opinión consultiva sobre si la elección del Comité de Seguridad Marftima hecha por Ia Asamblea el 15 de enero de 1959 se había hecho de acuerdo con la Convención constitutiva de la Organización. En su opinión consultiva del 8 de junio de 1960, la Corte declaró que dicho Comité no habla sido constituido de acuerdo. con la Convención, esto es, que el acto de la Asamblea era ilegal (ICJ Rep., 1960). 
del Acuerdo. También en este caso existen disposiciones relacionadas con las causas de ilegalidad, las partes que pueden recurrir a este procedimiento, plazo para recurrix, poderes de la Corte y efectos del fallo.

Cada uno de los dos tipos de soluciones descritos precedentemente se basa en diferentes supuestos y tiene diferentes implicaciones. En el primero - esto es, el que llamamos enfoque tradicional- el procedimiento tiene por objeto poner fin a la controversia. La decisión final puede o no contener un pronunciamiento sobre la legalidad del acto de la organización internacional, pero si se concluye que el mismo es ilegal, no por ello debe considerarse nulo o sin valor. En este caso, la función del órgano jurisdiccional consiste en decidir cuál es el derecho de las partes en la controversia, sin que este pronunciamiento altere necesariamente la estabilidad o la validez del acto que motivó la controversia.

En cambio, el propósito del contencioso de anulación es el de asegurar la integridad y la coherencia de un orden jurídico particular, para lo cual se establecen medios judiciales que hacen posible la eliminación de los actos que contravengan dicho orden jurídico. El procedimiento se dirige contra el acto presuntamente ilegal, y puede ser utilizado sin necesidad de demostrar la existencia previa de una controversia en sentido técnico ${ }^{5}$. Se trata de lo que la doctrina califica como "contencioso objetivo" en el sentido de que le basta, a quien lo promueve, invocar la violación de una regla de derecho o la violación de derechos emanados de una situación jurídica general e impersonal ${ }^{6}$. El contencioso está, en cambio, vinculado a un elemento temporal consistente en la fijación de un plazo, contado a partir de la adopción, publicación o notificación del acto, dentro del cual la acción contenciosa debe ser iniciada so pena de caducidad. Por otro lado, como el objetivo principal de la acción es el de restaurar el orden jurídico violado, el poder de la autoridad judicial que entiende el caso consiste en confirmar la legalidad del acto o declarar que el mismo es nulo.

Es obvio que la adopción de uno u otro sistema produce diferentes resultados tanto en la organización de los procedimientos como en la naturaleza y el alcance de la competencia del órgano jurisdiccional.

Desde que en el Comité de Fondos Marinos se empezó a discutir el establecimiento de una organización internacional para administrar la Zona y sus recursos, se planteó la necesidad de crear mecanismos y procedimientos para evitar o solucionar los conflictos que pudieran surgir entre la misma y los Estados miembros u

Ver del autor: Op cit. en nota 2.

'De Laubadère, Traité de Droit Administratif, 7ème ed., Vol. I, 1976, p. 511. 
otros sujetos que participarían en la realización de actividades en la Zona.

En el cumplimiento de sus funciones, los órganos de la Autoridad adoptarán decisiones y ejecutarán actos que afectarán los derechos y los intereses de los Estados miembros o de otros: sujetos involucrados en la realización de actividades en la Zona. En algunos casos, las Estados podrán ejercer el control previo de los actos a través de Ios procedimientos de adopción de decisiones, como en el caso de las decisiones que se deban adoptar por consenso (artículo 161, párrafo 7 d)). En otros casos, podrá solicitarse la opinión consultiva de la SGFM. Pero es este un mecanismo de alcance limitado ya que las opiniones consultivas no son obligatorias ni se emiten automáticamente, sino sólo cuando son requeridas de conformidad con los artículos 159, párrafo 10, y 189.

Dado que los órganos de la Autoridad podrán, en ciertas circunstancias, adoptar decisiones obligatorias contra la voluntad de algunos de sus miembros, se entendió, desde las etapas iniciales de las negociaciones, que era necesario establecer recursos mediante los cuales se pudiera impugnar los actos ilegales adoptados por aquélla.

En el texto actual no existe un procedimiento para obtener la anulación de los actos ilegales de la Autoridad diferente del procedimiento aplicable a otras controversias de la Parte XI.

Los autores del sistema especial no se atrevieron a establecer un verdadero control judicial de la legalidad de los actos de la Autoridad en forma similar a Io que se ha hecho en la CEE y en el Grupo Andino. En vez de ello, optaron por una solución según. la cual toda impugnación de un acto de la Autoridad hecha por un Estado Parte da lugar a una controversia con respecto a la cual la SGFM tiene poderes similares - pero no idénticos-, a los que posee con respecto a cualquier otra controversia relativa a las actividades en la Zona. Pero existen ciertos elementos que constituyen. vestigios del sistema contencioso de anulación tal como fue propuesto por algunos países ${ }^{7}$, como por ejemplo la enumeración de las causales por las cuales se puede alegar la ilegalidad de los actos (artículo $187 \mathrm{~b})$ ) o el establecimiento de límites a la competencia de la SCFM (artículo 191). Por ello puede decirse que en el sistema de la Convención el control de la legalidad de los actos de la Autoridad no se hace directamente atacando el acto impugnado para obtener su invalidación, sino indirectamente fallando en la controversia que ha sido causada por el acto.

AI elegir una fórmula híbrida - procedimiento de solución de controversias con elementos del contencioso de anulación- la Conferencia no sólo adoptó una solución cuya aplicación efectiva sus-

TEn particular la propuesta de Ios Estados Unidos, documento A/AC. 188/25. 
citará numerosos problemas sino que perdió la oportunidad de consagrar lo que hubiera sido el primer sistema de control de legalidad de los actos de una organización internacional con alcance universal.

No obstante ello, el hecho de que los Estados dispongan de un medio judicial para recurrir contra ciertas decisiones de la Autoridad significa, de todos modos, un notable avance en el terreno de los procedimientos de solución de controversias. Ello contribuye a la vez a fortalecer y expandir la organización internacional mediante el establecimiento de un mecanismo que asegurará el respeto al derecho y la protección de los intereses de los Estados miembros 8 .

Ta en 1950 Gros opinaba que un recurso contra, las decisiones de las organizaciones internacionales adoptadas en violación de sus estatutos tendría la doble ventaja de constituir "una mejora sobre los procedimientos actualmente posibles en tal hipótesis" y de estimular a los Estadso "a adherir a las organizaciones internacionales ya que podrian salvaguardar sus intereses y conservar una cierta libertad de acción en el marco de las organizaciones haciendo anular -por una jurisdicción imparcial- las decisiones adoptadas en exceso de competencia o abuso de poder" ("Le problème du recours jurisdictionel contre les décisions d'organismes internationaux" en $\mathrm{La}$ Teçhnique et les principes $d u$ droit pubtic. Etudes Scelle, 1950, x, p. 267). Traducción del autor. 